\title{
Evaluation of non-cost factors affecting the Life Cycle Cost: an exploratory study
}

\author{
Ayedh Alqahtani \\ Department of Civil Engineering, Curtin University, Perth, Australia \\ Andrew Whyte \\ Department of Civil Engineering, Curtin University, Perth, Australia
}

\begin{abstract}
:
Purpose - Identify the main non-cost factors affecting accurate estimation of LCC in building projects. Design/methodology/approach - Ten factors affecting LCC in building project cost estimates are identified through literature and interviews. A questionnaire survey is conducted to rank these factors in order of priority and provide the views of cost practitioners about the significance of these factors in the accurate estimation of life cycle cost. The data from 138 construction building projects completed in UK was collected and analysed via multiple-regression to discover the relationship between capital and life cycle costs and the relationship between non-cost factors and cost estimation at each stage of the life cycle (capital, operation, maintenance and LCC). Findings- The results of analysis of existing life cycle cost data of completing project and survey data from cost professionals are mostly consistent with many literature views and provide a reasonable description of the non-cost factors affecting the accuracy of estimates.

Originality/value- The value of this study is in the method used, which involves analysis of existing life data and survey data from cost professionals. The results provide a plausible description of the non-cost factors affecting the accuracy of estimates.
\end{abstract}

Keywords: Life cycle cost, non-cost factors, cost estimation, building projects, a questionnaire survey and multiple-regression.

Article Classification: Research paper

\section{Introduction:}

Life cycle cost (LCC) is one of the most crucial functions in decision making during the early phase of a project's life-cycle (Islam et al. 2015a). All decisions about the project and the implications for it require a range of stakeholders including the owner, contractor, designer, and lending company. They include economic analysis of a number of alternative project components, clarifying the feasibility of a project or identifying an initial cost of a project (Sonmez 2004). Accurate estimation of LCC will assist organisations in evaluating current assets and in making better decisions in the planning and building of new facilities (Islam et al. 2015b). It will aid the choice of optimum techniques and approaches for operation and maintenance and 'best' disposal of unneeded components. Previous studies identify limitations for using the concept of LCC as: a lack of predictive data, absence of a standardised methodology and incomprehension of the complex process (Alqahtani and Whyte 2013, Asjad et al. 2013, Minne and Crittenden 2015). In addition, current estimation methods (probability analyses, and statistical tools) have several disadvantages, such as being time consuming, being costly in method, the need for accurate information to improve the result, seeming to be problematic when applied to the early stages of the asset life-cycle due to a lack of information and the result may be inaccurate especially when applied on a system level (Alqahtani and Whyte 2013).

Knowledge gaps in research in the area of importance of the application of LCC and accurate estimation of it, especially for the building and construction industry, and the need for better cost estimation methodologies and tools, suggest that an alternative method might be more appropriate. To tackle some of the key barriers presented above and to provide a useful tool to decision makers to assist them in estimating the total cost of construction projects, a new LCC approach is required that develops methods for standard data tracking and a collection of procedural needs. Identifying the main factors impacting upon the value of LCC is the next step to developing a simplified model of LCC and attaining the most accurate LCC estimation. These factors can be classified under two categories; cost factors (represented by quantitative factors such as all cost items; foundation cost, elevator cost, roof cost etc.) and non-cost factors (represented by qualitative factors such as project type, project size etc.). 
The main objective of this paper is to identify the main non-cost factors affecting accurate estimation of LCC in building projects. In achieving this main objective, the sub-objectives of the study were formulated as:

1. Review literature to identify non-cost factors (variables) which are significantly affecting accurate estimation of LCC in building projects;

2. Conduct the survey research to rank these factors and provide the views of cost practitioners about how these factors can affect the accuracy estimation of LCC.

3. Analyse the existing data (building projects) to clarify the relationship between capital cost and running costs and use multiple regressions to conduct an empirical study that can clarify the relationship between capital cost, running cost, LCC and non-costfactors.

The structure of the remainder of this paper is as follows: the first section clarifies the research methodology of this study. Broad reviews of previous research are provided to identify non-cost factors. Subsequently the data collection of this research is presented and the results and data analysis determined are explained. Finally, concluding and discussion remarks are presented.

\section{Review of previous research to identify non cost factors}

Non-cost factors should be considered in the cost estimation process as they seem to play a significant role in the result of the estimation (Elhag et al. 2005). Liu and Zhu (2007) categorised the factors affecting cost estimation into two types, namely, idiosyncratic and control factors. Idiosyncratic factors involve elements outside the control of estimators such as weather condition, type of procurement system and other similar factors. Conversely, control factors comprise factors that estimators are able to determine, control and include in the process of cost estimation. This research will only focus on the latter type of non-cost factors.

The data of 30 projects was used to develop two Artificial Neural Networks (ANNs) models to predict the lowest tender price of primary and secondary school buildings (Elhag and Boussabaine 1998). The first model consists of four cost-influencing factors as input attributes and the second model involves 13 input cost variables. It was established that the more significance the factors contributed in developing an ANN model, the better the outcomes achieved.

Later Emsley et al. (2002) conducted a research aimed at comparing the performance of the estimation accuracy of two statistical methods, namely, regression analyses and neural networks. They used a data pool of 288 completed projects in the UK. They used 41 independent variables to develop both models and found that the necessary input (41 independent variables) was extensive, causing difficulties when applying it in the early design stages.

In another case study conducted by Attalla and Hegazy (2003) which was carried out to investigate the risky environment of reconstruction projects and identify the significant factors affecting their cost performance, they discovered that 18 factors have high impact on the cost performance of reconstruction by means of literature reviews, discussion with construction professionals and a questionnaire survey. All these factors were used to develop ANN and only 5 of them were used to develop a regression model to predict the cost performance of reconstruction projects. They concluded that ANNs produced accurate results.

In 2003, Skitmore and $\mathrm{Ng}$ conducted a study to develop several models for actual construction time and cost prediction when client sector, contractor selection method, contractual arrangement, project type, contract period, and contract sum were known. A total of 93 Australian construction projects were used to achieve the main objective of the study.

Independently, Li e t a 1., (2 005 ) applied the concept of stepwise regression to develop a cost model of office buildings in Hong Kong using the data of 30 completed office building projects. The results of their study provided a clear explanation about the relationship between a number of independent 
variables and total cost. They found that total floor area and total building height account for over 96 per cent of the accuracy of the model for reinforced office buildings. For steel office buildings, total floor area, average floor area and total building height account for over 95 per cent of the accuracy.

An et al., (2007) conducted a study to compare the performance of the two methods of estimating construction costs (Case-Based Reasoning (CBR) and ANN). The study included the data of 580 residential buildings and was carried out in Korea by general contractors between the years 1997 and 2002. Nine variables were considered as the input variables for the model based on the interviews with experts who had good experience of construction companies in Korea. In the CBR method, they applied the Gradient Descent Method (GDM) and regression analysis method to evaluate the weights of the variables. The result from the regression method was better than GDM and they found that only eight factors are significant. Two years later, they developed a case-based reasoning cost estimation model which was proposed to incorporate experience employing an analytic hierarchy process (AHP) (An et al. 2007). The same data and independent variable was used. The result of this study concluded that AHP provided a more accurate result but depended for expert experience and judgment than other approaches and therefore, this method generates both uncertainty and imprecision because of the requisite for human involvement and it may not provide the best results.

In 2007, a cost estimation model was developed by Wheaton and Simonton based on data available for over 60,000 properties (including 42,000 residential properties) and primarily concerned six American markets. Their work was concerned with the "true" trends of the cost during a period of 35 years and they analysed the correlation between costs and building activity.

In Australia, Aibinu and Pasco (2008) studied the importance and accuracy of cost estimation of building construction projects. Their study involved 56 building construction projects and the survey of 102 companies. They reviewed previous research and identified and collected the main factors affecting accuracy of the cost estimation which included factors of project value, gross floor area, number of storeys, location, procurement route, project type, type of structure and price intensity. The importance levels of these factors were further investigated using a traditional multiple linear regression technique. Their results indicated that th e size of project (project value, number of storeys and gross floor area) is the most influential factor affecting cost estimation of a building construction project in Australia.

Moving from Australia to Germany, based on 70 German residential properties, the relevant building construction cost drivers were identified (Stoy et al. 2008). They reviewed the previous studies, supplied a list of cost drivers and re-examined experts in interviews. The outcome of this introductory study was a ranked list of more than 90 cost drivers. In addition, their fundamental relationships were examined in a regression model. They concluded that compactness of the building, number of elevators, size of the project, expected duration of construction, proportion of openings in external walls, and region are the most important variables affecting building construction cost. This study's experts ranked four of the six recognised variables of the model amongst their ten important variables.

Applications that use a series of artificial intelligence (AI) techniques include Cheng et al. (2009) to predict project cash flow trends and gain strategic control over project cash flow. In their work, fu z z y logic and neural network are used to develop a neural-fuzzy-model which enables dealing with uncertainties and knowledge mapping. A genetic algorithm was used to optimise the membership functions of the model. They used the data of 52 construction projects, with 9 significant factors in order to develop the model. These factors were number of floor; contract cost, total area, duration, cost ratio of foundation engineering, cost ratio of structural engineering, cost ratio of decoration engineering, cost ratio of facilities and cost ratio of indirect cost.

Elkassas, Mohamed and Massoud (2009) conducted research to estimate the financial cost of construction projects using the neural network model. They created three back-propagation neural network models to predict the financial cost of three types of construction project; namely, pipeline 
projects, industrial projects and building projects. 215 of the building projects were used to create, train and test the models. The type of project, duration of project, estimation contract value, advance payment, time lag, interest rate, mark-up, time unit of the first payment, retention, project location, weather conditions, safety condition, possibility increment in the project duration, owner payment, delay and inflation were considered as important variables in the input layer. They found that the neural network model provided a clear and accurate estimation.

Again in terms of ANNs, Chang Sian et al., (2010)sought to predict maintenance costs and a budget for University buildings using the neural networks model. This study developed four neural networks models and their results were compared with the result from the regression approach in order to identify which model had the least mean square error. There were four main factors affecting the maintenance costs and budget of the university buildings: building age, number of floors, number of classrooms and number of elevators. Four neural networks were classified based on the number and type of variables in the input layer for each model. The research concluded that the prediction accuracy of the neural networks model is superior to the regression approach.

Cheng et al. (2010) combined artificial intelligence with the concept of fuzzy neural networks to estimate costs both overall (total cost) and category (engineering) cost. They considered 10 factors as input variables (significant variables) to estimate overall cost using qualitative and quantitative factors. These factors were floors underground, total floor area, floors above ground, site area, number of households, households in adjacent buildings, soil condition, seismic zone, interior decoration and electro-mechanical infrastructure.

In another study, the data of 164 apartment buildings from 15 housing complex projects in Korea were utilised to create a CBR cost estimate model for building projects. A Euclidean distance concept and genetic algorithms were used ( $\mathrm{Ji}$ et al. 2011). Based on a previous research review and an expert interview, twelve variables were employed to assign the weight values of cases and to evaluate case similarity. These factors were number of households, gross floor area, number of unit floor households, number of elevators, number of floors, number in household scale(s), number of households of unit floor per elevator, height between stories, depth of pit, roof type, hallway type and structure type (RC).

Moving to America, data collected from 20 U.S. building projects were used to develop a conceptual cost estimating model (Sonmez, 2011). The model was created based on integrated neural networks and the bootstrap resampling technique. A total of 20 factors were used to develop this model and these factors involved information of time and location of project, project duration, project characteristics such as total gross building area and number of storeys, site conditions, structural frame and exterior finish types.

In the Middle East, an artificial neural network model was used to develop a model to estimate the cost of the structure system of the building at an early stage in the Gaza Strip (Mohammed and Mamoun 2011). The data of 71 completed building projects in the Gaza Strip were used along with seven significant parameters considered as input variables of the model. The sensitive analysis technique was applied to recognise the most significant variables affecting the result of the model and they concluded that the ground floor area, number of storeys, type of foundation and number of elevators are the most significant factors affecting the model.

A practical hybrid conceptual cost estimating model for large building projects was presented by Kim et al., (2012), including multiple mixed-use buildings. They tested the accuracy and the efficiency of the proposed model through a case study involving eight mixed-use projects. For the test of the model, input variables consisted of only project characteristics such as type of project and gross floor area. This built upon previous work by Kim et al., (2005), who adopted hybrid models of neural networks and genetic algorithms to predict the preliminary cost of residential buildings in Seoul, Korea. A genetic algorithm was used to optimise the parameter of the neural network model and obtain a set of trained weights for the model. They used the data of 498 projects of residential buildings built by general contractors between 1997 and 2000. Eight variables were selected to be input variables of the 
model. These variables were total floor area, number of stories, total units, duration, type of roof, type of foundation, type of basement and grades of finishing.

Jin et al. (2012) conducted a research to improve performance of cost estimation. They applied multiple regression analysis and found that site area, underground area, ground area, building area, number of underground floors, number of floors and landscape area were the most effective parameters influencing the proposed model.

The literature review and analysis of previous techniques leads this study to recognising the influential parameters in construction cost. The process of influential parameters identification facilitates the elimination of non-influential parameters. The important non-cost factors affecting the estimation process of a project in construction are summarized in table 1 .

\section{Research Methodology}

Two methods of data collection were used to achieve the study objectives. In order to achieve objective 2 , a structured questionnaire was designed for data collection. The piloting study was conducted by interviewing the individuals in charge of estimating. They were tested for the language and wording of questions, clarified the ambiguous question and proved that the respondents were able to answer the question which assisted in the achievement of the objective of the research. They generated questions concerning clarification of certain terms and requested the modification of some questions.

A sample, covering quantity surveyors, cost estimators, cost engineers, and project managers who were involved in the construction industry, was selected for the survey. The first section of the questionnaire provided general information about the participation of the respondents in it. This part was aimed at reflecting the strength of the respondents' characteristics, and consequently to show the degree of reliability of the information provided by them. The second part of the questionnaire aimed to study the perspective of the respondents of the essential factors affecting the accuracy of LCC estimation in construction and building projects. These factors are summarised in the table 1 below.

\begin{tabular}{|ll|}
\hline Factors affecting the accuracy of LCC \\
\hline 1. & Number of stories \\
\hline 2. & Type of building \\
\hline 3. & Gross floor area \\
\hline 4. & Project life \\
\hline 5. & Location \\
\hline 6. & Roof types \\
\hline 7. & Foundation types \\
\hline 8. & Number of elevators \\
\hline 9. & Type of structure \\
\hline 10. & Inflation rate \\
\hline
\end{tabular}


The respondents were asked to rate the final 10 factors that could affect the accuracy of the estimation of LCC. They were asked to rank the importance of each factor on a 5-point Likert scale. The main survey was distributed to 203 professionals who often deal with cost issues in the construction industry.

In order to achieve objective 3, data were collected from the files of 138 construction building projects completed in the UK. The data were obtained from the Building Cost Information Service (BCIS) database of The Royal Institution of Chartered Surveyors (RICS). This data covered all the main costs of the principal sub-components of the building projects. Information obtained in respect of each project included number of storeys, type of building, gross floor area, location, number of elevator, type of structure, roof type, foundation type and project life and inflation rate. The data were used to clarify the relationship between capital costs and running costs and to clarify and identify the relationship between capital, running and LCC and non-cost factors by using the multiple regression method.

\section{Data analysis and results of survey}

Response rate and characteristic of sample from questionnaire:

After distributing the survey, $124(61 \%)$ were returned by the respondents over a period of time. Cronbach's alpha was used to measure the reliability of the questionnaire, which could be defined as the degree to which the method of data gathering produces consistent results when the measurement was repeated (Mark 2010). It was calculated as 0.862 for the questionnaire which indicates an excellent reliability of the entire survey. Therefore, it can be supposed that the researcher concluded that the questionnaire was valid and reliable for the population sample and could be distributed.

In terms of the employment position of the respondents, $21 \%$ (26 of 124) of respondents were directly involved in a quantity surveyor position, $17 \%$ (33 of 124) of the respondents were in a cost estimators position, 24\% (30 of 124)were in a project manager position and28\% (35 of 124) were in a cost engineer position. The respondents had key positions that ensured quality information.

In an attempt to determine respondents' education qualifications and therefore the skill base, respondents had been requested to provide their highest education qualification attained. The majority of the respondents in this sample $(107 ; 86 \%)$ reported having graduate or postgraduate qualifications, while $5(4 \%)$ had a non-academic degree. It can be assumed that the respondents in this sample had sufficient knowledge and were capable of understanding the concepts and theories for estimation and the controlling cost of projects.

With regard to the respondents' experience, the results illustrate that the majority of the respondents $(86.0 \%)$ in the sample had experience of more than 5 years, and more than half of the respondents (55.5\%) had experience of more than 10 years. These results supported the notion that the data gathered reflected its intended purpose. The respondents had responsible positions in their work and were able to provide accurate and specific data.

\section{Ranking factors:}

The data received was analysed by a relative importance index method (RII) to determine the comparable significance of the factors affecting accuracy of LCC estimation in building projects The relative importance index was evaluated using the following equation (Lim and Alum 1995):

$$
\boldsymbol{H}=\frac{(5 \mathrm{n} 5+4 \mathrm{n} 4+3 \mathrm{n} 3+2 \mathrm{n} 2+1 \mathrm{n} 1)}{\mathrm{AN}} \ldots
$$

Where: $\mathrm{n} 1=$ number of respondents who answered "not at all important", $\mathrm{n} 2$ = number of respondents who answered "not very important", 
$\mathrm{n} 3=$ number of respondents who answered "somewhat important",

n4 = number of respondents who answered "very important",

n5 = number of respondents who answered "extremely important",

A is the highest weight (5 in the research) and $\mathrm{N}$ is the total number of samples (124 samples in this research). The relative importance index ranges from 0 to 1 . Table (2) below illustrates the overview of relative importance and the ranking of each factor.

\section{One- Way ANOVA F Test:}

A one-way analysis of variance (ANOVA) test was used to measure the difference in the means for the four groups of opinion (quantity surveyors, cost estimators, project managers and cost engineers) at significance level a $=0.05$ (Mark 2010). There are three assumptions required using a one-way ANOVA F test:

a) Independence: each respondent should participate only once in the study, and should not affect the participation of others. This assumption was considered both before and during data collection.

b) Homogeneity of variance: the population variances are equal in each set of scores. This assumption was assessed using Leven's test for homogeneity of variance. Levene's statistic was non-significant, p-vale more than 0.05 , and thus the assumption of homogeneity of variance was not violated as the results in table (2) show (Mark 2010).

c) Normality: the sample value comes from a normally distributed population. The normality test was assessed based on the results of both skewness and kurtosis which was very close to the zero and the $\mathrm{Z}$ scores for both tests was less than \pm 1.96 . This means that the sample of data was probably drawn from a normally distributed population.

Table (2) shows the main results of the ANOVA test. These results indicate that there are no differences between the groups regarding the ranking of factors affecting accuracy of LCC estimation in building projects at significance level $\mathrm{a}=0.05$ and $\mathrm{F}$-critical $=4.5$.

\begin{tabular}{|c|c|c|c|c|c|c|c|c|}
\hline \multirow[t]{2}{*}{ Factors } & \multirow{2}{*}{$\begin{array}{c}\text { The } \\
\text { Relative } \\
\text { Importance } \\
\text { Index }\end{array}$} & \multirow[b]{2}{*}{$\begin{array}{l}\text { Final } \\
\text { Rank }\end{array}$} & \multicolumn{4}{|c|}{ Test of Homogeneity of Variances } & \multicolumn{2}{|c|}{ ANOVA } \\
\hline & & & $\begin{array}{l}\text { Levene } \\
\text { Statistic }\end{array}$ & df1 & df 2 & P-vale & $\mathrm{F}$ & P-vale \\
\hline Project life & 0.80 & 1 & 1.366 & 3 & 119 & 0.25 & 1.314 & 0.269 \\
\hline Inflation rate & 0.76 & 2 & 1.844 & 3 & 119 & 0.12 & 1.414 & .234 \\
\hline Type of building & 0.75 & 3 & 1.316 & 3 & 119 & 0.27 & 2.161 & 0.077 \\
\hline Type of structure & 0.74 & 4 & 2.473 & 3 & 119 & 0.06 & 0.456 & 0.768 \\
\hline Location & 0.72 & 5 & 1.546 & 3 & 119 & 0.19 & 1.274 & 0.284 \\
\hline Gross floor area & 0.70 & 6 & 0.728 & 3 & 119 & 0.57 & 0.749 & 0.561 \\
\hline Roof types & 0.67 & 7 & 0.578 & 3 & 119 & 0.68 & 0.772 & 0.546 \\
\hline Number of stories & 0.65 & 8 & 2.481 & 3 & 119 & 0.06 & 0.792 & 0.533 \\
\hline Number of elevators & 0.64 & 9 & 0.620 & 3 & 119 & 0.65 & 0.449 & 0.773 \\
\hline Foundation types & 0.63 & 10 & 1.950 & 3 & 119 & 0.11 & 0.599 & 0.664 \\
\hline
\end{tabular}

Table 2 RII, Levene test and ANOVA results 


\section{Analysis of the existing data}

Identify the relationship between capital and running costs:

Data on 138 actual building projects constructed in the United Kingdom (UK) have been collected and used in this study. Table 3 below provides more details of the data collected concerning the type of structure, number of stories, gross floor area, type of building, location, number of elevators and type of foundation. The LCC was calculated four times based on different project life and different discount rate:

1. Case $1:$ LCC at 30 years and Discount rate $=2 \%$

2. Case2: $\mathrm{LCC}$ at 60 years and Discount rate $=2 \%$

3. Case $3: \mathrm{LCC}$ at 30 years and Discount rate $=3.5$

4. Case4: $\mathrm{LCC}$ at 60 years and Discount rate $=3.5 \%$

The significance of considering LCC in cost estimation and as a tool for making decisions can be noted from figures 1 . Both the capital costs and running costs (maintenance and operation costs) for each building type have been considered. In most cases running costs are over $50 \%$ of the total LCC of the building illustrated.

\begin{tabular}{|c|c|c|c|c|c|}
\hline Project factors group & sub-group & Number of project & Project factors group & sub-group & Number of project \\
\hline \multirow[t]{4}{*}{ Location } & England & 95 & \multirow[t]{8}{*}{ Gross floor area } & $15000-24999 \mathrm{~m} 2$ & 2 \\
\hline & Scotland & 29 & & $25000-35000 \mathrm{~m} 2$ & 1 \\
\hline & Wales & 12 & & $10000-14999 \mathrm{~m} 2$ & 3 \\
\hline & North Ireland & 2 & & $5000-9999 \mathrm{~m} 2$ & 11 \\
\hline \multirow{9}{*}{ Number of stories } & 0 & 19 & & $2500-4999 \mathrm{~m} 2$ & 25 \\
\hline & 1 & 37 & & $1000-2499 \mathrm{~m} 2$ & 48 \\
\hline & 2 & 50 & & $500-999 \mathrm{~m} 2$ & 19 \\
\hline & 3 & 21 & & less than $500 \mathrm{~m} 2$ & 29 \\
\hline & 4 & 7 & \multirow[t]{3}{*}{ Type of structure } & $\mathrm{RC}$ frame & 20 \\
\hline & 5 & 0 & & steel frame & 89 \\
\hline & 6 & 2 & & timber frame & 29 \\
\hline & 7 & 1 & \multirow[t]{4}{*}{ Foundation } & Piles & 33 \\
\hline & 8 & 1 & & strip and pad & 84 \\
\hline \multirow[t]{9}{*}{ Number of elevators } & 0.00 & 75 & & raft & 4 \\
\hline & 1.00 & 44 & & trench & 17 \\
\hline & 2.00 & 11 & \multirow[t]{7}{*}{ Type of building } & 1-Recreational building & 14 \\
\hline & 3.00 & & & 2-Commerical building & 27 \\
\hline & & 4 & & & \\
\hline & 6.00 & 2 & & 3- education building & 36 \\
\hline & 7.00 & & & 4- Health building & 25 \\
\hline & & 1 & & & \\
\hline & 10.00 & 1 & & 5- Residential building & 36 \\
\hline \multicolumn{3}{|c|}{ Inflation rate; LCC was calculated in 2.9 and $4.4 \%$ inflation rate } & \multicolumn{3}{|c|}{ Project life; LCC was calculated in 30 and 60 years } \\
\hline
\end{tabular}

Table 3 data descriptive of 138 projects 
The pattern of running costs also varies between building types. In the commercial building, the running costs are between $60-74 \%$ of the LCC in most projects, while for residential building running costs they are between $40 \%-55 \%$ of the LCC in most projects (as in figure 1).

The reason for the main difference in the running costs between buildings is the number of hours and the occupancy of the buildings. Buildings in health and commercial categories are usually in use 24 hours a day throughout the year. This will lead to an increase in the operation and maintenance costs of these buildings compared with other types of building as is shown in figure 1.

In addition, the result gives a snapshot of the effect of project life on the total value of LCC. It is clear that the percentage of running costs increases by approximately 5\% at discount rate of $2 \%$ and $3 \%$ at discount rate of $3.5 \%$ during the period of analysis from 30 to 60 years for the five building types.

Furthermore, the result illustrates that the discount rate has a significant impact on the total value of LCC. It can be seen that the percentage of running costs was decreased by approximately 5\% at the 30 years period of analysis and by $8 \%$ at 60 years period of analysis which caused the discount rate from $2 \%$ to $3.5 \%$ for the five building types.

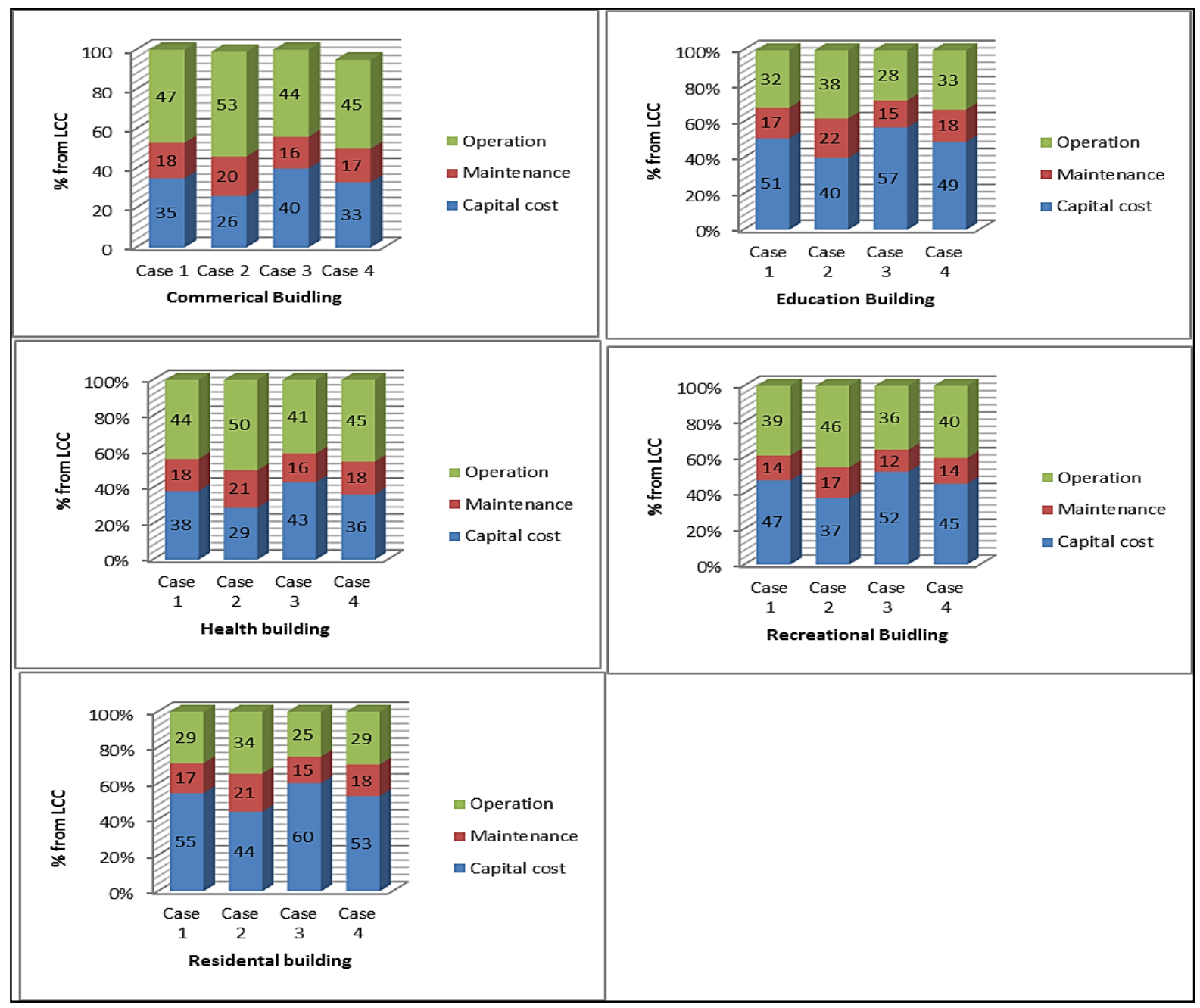

Figure 1 Life cycle cost result for five buildings

It is clear that considering LCC as part of the decision support tools will aid stockholders in their evaluation of the most desirable alternative and their decision of which projects to exclude. They will then be able to utilise better resources with a higher return in the remaining projects to preserve the projects with the highest return or value. In addition, implementation of LCC provides valuable and maximum information at an early stage, supporting the decrease in waste and the increase in efficiency of design and construction together with operation and maintenance. 


\section{Multiple regression model}

Non-cost factors were further investigated utilising the multiple linear regression technique with the help of the Statistical Package for Social Sciences software (SPSS). The independent variables are those factors listed in table 1 with the exception of the roof type factor which was excluded as the majority of projects studied used more than one type. Inflation rate, project life, number of storeys, number of elevators and gross floor area were involved in the regression model as scale variables while other factors were included as categorical variables according to the groupings shown in table 3 below.

Multiple regression models are formed as the following equation (Jin et al. 2012):

$$
\mathrm{LCC}=\mathrm{a}+\mathrm{b}_{1} * \mathrm{X}_{1}+\mathrm{b}_{2} * \mathrm{X}_{2}+\ldots . .+\mathrm{b}_{\mathrm{n}} * \mathrm{X}_{\mathrm{n}}
$$

Where: $\quad a=$ intercept, $b_{1}$ to $b_{n}=$ regression coefficients and $X_{1}$ to $X_{n}=$ independent variables.

As mentioned previously, 138 completed projects were used to develop regression models. In general, the variables with p-value close to or less than 0.05 are considered to have important contribution to the LCC (Ontepeli 2005). Table 4 below illustrates the result of multiple regressions for four models.

\begin{tabular}{|c|c|c|}
\hline Models & Important factors & $\mathrm{R}^{2}$ (adjusted) \\
\hline \multirow[t]{5}{*}{ Capital costs } & Type of building & \multirow[t]{5}{*}{0.905} \\
\hline & Number of stories & \\
\hline & Gross floor area & \\
\hline & Number of elevators & \\
\hline & Type of structure & \\
\hline \multirow[t]{6}{*}{ Operation costs } & Type of building & \multirow[t]{6}{*}{0.955} \\
\hline & Gross floor area & \\
\hline & Number of elevators & \\
\hline & Inflation rate & \\
\hline & Project life & \\
\hline & Location & \\
\hline \multirow[t]{6}{*}{ Maintenance costs } & Type of building & \multirow[t]{6}{*}{0.940} \\
\hline & Gross floor area & \\
\hline & Number of elevators & \\
\hline & Inflation rate & \\
\hline & Project life & \\
\hline & Location & \\
\hline \multirow[t]{6}{*}{ LCC } & Number of stories & \multirow[t]{6}{*}{0.967} \\
\hline & Gross floor area & \\
\hline & Number of elevators & \\
\hline & Inflation rate & \\
\hline & Project life & \\
\hline & Type of structure & \\
\hline
\end{tabular}

Table 4 Results of multiple regression analysis. 
From the results (Table 4), LCC is influenced by project life, gross floor area, number of storeys and elevators, type of structure and inflation rate. Type of building, number of storeys, gross floor area, number of elevators and type of structure are the important factors affecting the estimation of capital costs. However, running cost is influenced by all nine factors except number of storeys, type of structure and type of foundation.

\section{Discussion}

The results show that the respondents ranked project life in the first position with a relative importance index (RII - 0.8), which indicates the value of a project's life is an important part in a LCC application. Buildings consist of several components and the components will have varying lifespans. Some components will expect to retain their performance over the entire project's life, such as the foundation, whereas others will require frequent renewal or upgrading such as the electrical and mechanical systems. In addition, the result of the multiple-regression model indicates that both running and life cycle costs are influenced by the project life and it is evident that increasing the project life leads to increase in the running and life cycle costs. This result is in line with the results of Rudbeck (2001), Stillman (1992) and Bourke and Davies (1999). An appropriate description of this agreement is that an estimate of the project life based on the assessment of the building component's service life can be used in conjunction with LCC to provide a clear picture of the status of the building's assets. Generally the longer the life of the building project leads to higher costs because more resources (labours, materials and equipment) will be required.

The second important factor ranked by respondents was inflation rate (RII=0.76). The general state of the economy will affect the life cycle cost of building projects. Inflation can cause an increase in the initial estimates of the life cycle cost of a building project. Inflation may have been considered in the initial estimates, but if the rate of inflation rises above the estimated level throughout the project's life, then the initial life cycle cost estimate will be exceeded. The result of multiple regression confirms that both running and life cycle costs are influenced by inflation rate. The results of Elkassas, et al (2009) and Ashworth (2010) are similar to this research's finding. This factor cannot be ignored, especially, when the LCC approach is used to evaluate options.

Type of building (RII $=0.75$ ) was ranked as the third factor affecting accuracy of LCC estimation in building projects. The total amount of cost of design, construction and maintenance and operation will depend on the degree of specialisation of the project and the type of the material to be used. The results of multiple regressions clarify that type of building influences the estimation of capital, operation and maintenance costs. The results of AL-Hajj (1991), Aibinu and Pasco, (2008), E.M. Elkassas, et al., (2009), Elhag and Boussabaine, (1998), Kim et al., (2012) and Martin Skitmore and Thomas Ng, (2003) agreed with the results of this study. For example, AL-Hajj (1991) developed several CSI models; general model (for all types of building) and specific model (for particular buildings such as for education, residences and laboratories. He found that models of specific buildings have a higher accuracy than the general model. This implies that the type of building affects the result of the estimation. In this case, the type of project affects the estimation process.

The fourth important factor ranked by respondents was type of structure $(\mathrm{RII}=0.74)$. The cost of the type of structure is also variable. For example, the steel structure is the cheapest option in terms of structure costs alone and the best and most popular solution for multi-storey flooring in some countries. This variation in the cost also depends on several factors, such as the price of the material. The results of Aibinu and Pasco (2008), Ji, et al., (2011), Kim, et al., (2012), Akintoye (2000), Elhag et al., (2005) and Odusami and Onukwube (2008) coincide with this finding. However, there is no relationship between this factor and the estimation of both operation and maintenance costs as found in the multiple regression result.

Table (2) shows that respondents ranked the location ( $\mathrm{RII}=0.72$ ) as the fifth factor affecting accuracy of LCC estimation in building projects. The location of the project affects the LCC of the building project by conditions imposed by specific location. A delay in resources deliveries may occur and large vehicles 
may be damaged when the transportation route is poor. This situation will lead to an increase in costs. Moreover, if there is a long distance to transport these resources it may lead to increased transport charges. Labour availability is a further problem as each location has diversity in the number of available skilled and unskilled labourers. The labour cost will be increased if it is necessary to import labour from another location. The research results of E.M. Elkassas, et al., (2009), An, et al (2007), Elhag and Boussabaine (1998), Akintoye (2000), Elhag et al., (2005) and Odusami and Onukwube (2008) show similar results in that every building project's location has its own characteristics. A building project's location differs from one place to another in terms of labour costs, the cost of equipment, the costs and accessibility of materials and also accommodation. Furthermore, the result of multiple regression concluded that this factor affects the estimation of operation and maintenance costs.

Gross floor area and type of roofs were ranked 6th and 7th by respondents with RII of 0.70 and 0.67 respectively. The relationship between type of roof and cost estimation did not agree via multiple regression as stated previously but they did conclude that gross floor area has a significant impact on the estimation of capital, operation, maintenance and life cycle costs. The large area of the building would require additional costs for the resources utilised to carry out all the design, construction, operation and maintenance tasks. In addition, there are numerous types of roof used in building projects and the costs of the different styles vary. A flat roof is likely to be more expensive than a pitched roof of comparable quality due to the spanning of large areas with roof trusses rather than deep beams. Consequently, these factors can affect the LCC of building projects as both the construction and maintenance costs increase. These results are consistent with the findings of previous research undertaken.

As shown in table 2, the respondents ranked the number of storeys, number of elevators and foundation types as the three factors least affecting accuracy of LCC estimation in building projects. They believe that if the project includes an elevator, the LCC would increase due to the increase in the resource, operation and maintenance costs. This result is similar to multiple regression for all four models. Similarly, the LCC of tall buildings is greater than those of low-rise buildings. Construction costs for taller buildings tend to rise due to the costs of increased loads, roof size, foundation resources, and elevators. However, the multiple-regression indicated that this factor only affects the estimation of capital costs and has less impact on the estimation of both operation and maintenance costs. In addition, there are several types of foundation selecting based on certain characteristics of building design such as the type of structure. The cost of the foundation varies. Pile and raft foundations are more expensive than ordinary foundations. The multiple regression results concluded that there is no relationship between this factor and all four estimation costs. It may affect the estimation costs when considered as cost factors (the total cost of foundation) instead of non-cost factors (the type of foundation). The results of Ji, et al., (2011), Stoy, et al., (2008), Sonmez, (2008); Mohammed and Mamoun, (2011), Sonmez (2011) and Chang et al., (2010) did not agree with this finding. The reason behind this is that the majority of respondents believed that these three factors have more impact on the capital costs and less effect on operation and maintenance costs.

\section{Conclusion:}

Non-cost factors affecting LCC in building projects were reviewed based upon research work carried out in different countries. The results of these studies varied based on the different goals and purposes required to be achieved when the research was conducted.

A survey was developed and used to rank these factors and provide the views of cost practitioners about how the factors could affect the accuracy estimation of LCC. Ten factors affecting LCC were identified through literature and a pilot study.

ANOVA test revealed that a strong agreement between quantity surveyors, cost estimat ors, project managers and cost engineers existed in the ranking of the cost factors. The relative importance index computed for each factor ranged between 0.80 and 0.63 . This result suggests that there is no significant variation in the ranking of each factor. However, the project life was ranked top followed by inflation 
rate. The third and fourth ranks were type of building and structure with the foundation type occupying the lowermost rank.

Multiple-regression was then developed and used to clarify the relationship between capital cost and running costs. It was used to conduct the empirical study that clarified the relationship between capital cost, running cost and LCC and non-cost factors. The results of these studies also varied based on the goals and purposes of estimation. Gross floor area and number of elevators have significant impact in the estimation of all costs of the four models

The results of this study are mostly consistent with many literature views. However, the foundation type factor was found to be an insignificant factor for all costs of the four models. As identified earlier, this factor may affect the estimation costs when considered as cost factors (total cost of foundation) rather than non-cost factors (type of foundation).

The value of this study is in the method used, which involves analysis of existing life data and survey data from cost professionals. The results provide a plausible description of the non-cost factors affecting the accuracy of estimates. It is recommended that stockholders give greater consideration to the non-cost factors identified as being of greater importance in order to attain more accurate estimates. Implementation of the LCC may help the client to evaluate project viability and make a viable decision.

Also utilising LCC will assist the project management teams with choosing the best alternative from options based on economic criteria. This will enable increased owners' satisfaction and the most useful approach to procurement. They will be able to identify cost drivers, predict future budget requirements and control programmers and minimise total cost. Moreover, they can make a decision about whether to continue or abort the project by analysing all the costs of it. LCC can be used to create a significant decisions policy, design trade-offs and select a contractor when the project is placed for tender.

\section{References:}

Aibinu, A. A. and Pasco, T. (2008) "The accuracy of pre-tender building cost estimates in Australia", Construction Management and Economics, Vol. 26 No. 12, pp. 1257-1269.

Al-Hajj, A. (1991) Simple cost-significant models for total life-cycle costing in buildings, , University Of Dundee.

Alqahtani, A. and Whyte, A. (2013) "Artificial Neural Networks Incorporating Cost Significant Items towards Enhancing Estimation for (life-cycle) Costing of Construction Projects", Construction economic and building, Vol. 13 No. 3, pp. 51-64

An, S.-H., Kim, G.-H. and Kang, K.-I. (2007) "A case-based reasoning cost estimating model using experience by analytic hierarchy process", Building and Environment, Vol. 42 No. 7, pp. 2573 2579.

Asjad, M., Kulkarni, M. and Gandhi, O. P. (2013) "A life cycle cost based approach of O\&M support for mechanical systems", International Journal of System Assurance Engineering and Management, Vol. 4 No. 2, pp.159-172.

Attalla, M. and Hegazy, T. (2003) "Predicting Cost Deviation in Reconstruction Projects: Artificial Neural Networks versus Regression", Journal of Construction Engineering and Management, Vol. 129 No. 4, pp.405-411. 
Chang Sian, L., Pei Jia, C. and Sy Jye, G. (2010) "Application of back-propagation artificial neural network to predict maintenance costs and budget for university buildings", 2010 Sixth International Conference on Natural Computation, 10 Aug, Yantai, Shandong, pp. 546-1551.

Cheng, M.-Y., Tsai, H.-C. and Liu, C.-L. (2009) "Artificial intelligence approaches to achieve strategic control over project cash flows", Automation in construction, Vol. 18 No. 4, pp. 386-393.

Cheng, M.-Y., Tsai, H.-C. and Sudjono, E. (2010) "Conceptual cost estimates using evolutionary fuzzy hybrid neural network for projects in construction industry", Expert Systems with Applications, Vol. 37 No. 6, pp. 4224-4231.

E.M. Elkassas, H.H. Mohamed and Massoud, H. H. (2009) "the neural network model for predicting the financial cost for construction projects", Int. J. of Project Organisation and Management, Vol. 1 No. 3, pp. $321-334$.

Elhag, T., Boussabaine, A. and Ballal, T. (2005) "Critical determinants of construction tendering costs: Quantity surveyors" standpoint', International Journal of Project Management, Vol. 23 No. 7, pp. 538-545.

Elhag, T. M. S. and Boussabaine, A. H. (1998) "An artificial neural system for cost estimation of construction projects", 14th Annual ARCOM Conference, University of Reading, U.K.: Association of Researchers in Construction Management, pp. 219-226.

Emsley, M. W., Lowe, D. J., Duff, A. R., Harding, A. and Hickson, A. (2002) "Data modelling and the application of a neural network approach to the prediction of total construction costs", Construction Management and Economics, Vol. 20 No.6, pp. 465-472.

Islam, H., Jollands, M. and Setunge, S. (2015a) "Life cycle assessment and life cycle cost implication of residential buildings -A review", Renewable and Sustainable Energy Reviews, Vol. 42 No. 0, pp. 129-140.

Islam, H., Jollands, M., Setunge, S. and Bhuiyan, M. A. (2015b) "Optimization approach of balancing life cycle cost and environmental impacts on residential building design", Energy and Buildings, Vol. 87 No.0, pp. 282-292.

Ji, S.-H., Park, M. and Lee, H.-S. (2011) "Cost estimation model for building projects using case-based reasoning", Canadian Journal of Civil Engineering, Vol. 38 No. 5, pp. 570-581.

Jin, R., Cho, K., Hyun, C. and Son, M. (2012) "MRA-based revised CBR model for cost prediction in the early stage of construction projects", Expert Systems with Applications, Vol. 39 No. 5, pp. 5214-5222.

Kim, G., Seo, D. and Kang, K. (2005) "Hybrid Models of Neural Networks and Genetic Algorithms for Predicting Preliminary Cost Estimates", Journal of Computing in Civil Engineering, Vol. 19 No. 2, pp. 208-211.

Kim, H.-J., Seo, Y.-C. and Hyun, C.-T. (2012) "A hybrid conceptual cost estimating model for large building projects", Automation in construction, Vol. 25 No.0, pp. 72-81.

Li, H., Shen, Q. and Love, P. E. (2005) "Cost modelling of office buildings in Hong Kong: an exploratory study", Facilities, Vol. 23(9/10), pp. 438-452.

Lim, E. C. and Alum, J. (1995) "Construction productivity: Issues encountered by contractors in Singapore", International Journal of Project Management, Vol. 13 No.1, pp. 51-58. 
Mark, B. (2010), Basic business statistics : concepts and applications, Frenchs Forest, N.S.W.: Frenchs Forest, N.S.W. : Pearson Australia.

Martin Skitmore, R. and Thomas Ng, S. (2003) "Forecast models for actual construction time and cost", Building and Environment, Vol. 38 No. 8, pp. 1075-1083.

Minne, E. and Crittenden, J. (2015) "Impact of maintenance on life cycle impact and cost assessment for residential flooring options", The International Journal of Life Cycle Assessment, Vol. 20 No.1, pp. 36-45.

Mohammed, A. and Mamoun, A. (2011) "Early Stage Cost Estimation of Buildings Construction Projects using Artificial Neural Networks", Journal of Artificial Intelligence, Vol. 4 No.1 , pp. 63-75.

Ontepeli, M. (2005), Conceptual cost estimating of urban railway system projects, Middle East Technical University (METU).

Sonmez, R. (2004) "Conceptual cost estimation of building projects with regression analysis and neural networks", Canadian Journal of Civil Engineering, Vol. 31 No.4, pp.677-683.

Sonmez, R. (2008) "Parametric Range Estimating of Building Costs Using Regression Models and Bootstrap", Journal of Construction Engineering and Management, Vol. 134 No.12, pp. 10111016.

Sonmez, R. (2011) "Range estimation of construction costs using neural networks with bootstrap prediction intervals", Expert Systems with Applications, Vol. 38 No. 8, pp. 9913-9917.

Stoy, C., Pollalis, S. and Schalcher, H. (2008) "Drivers for Cost Estimating in Early Design: Case Study of Residential Construction", Journal of Construction Engineering and Management, Vol. 134 No. 1, pp. 32-39.

Wheaton, W. C. and Simonton, W. E. (2007) "The secular and cyclic behavior of 'true' construction costs", The Journal of Real Estate Research, Vol. 29 No. 1. 